\title{
O Supremo Tribunal Federal e os bloqueios judiciais nas ações de saúde: perspectiva crítica e a necessidade de organização do sistema
}

The Supreme Court and the judicial attachments in the health's lawsuit: critical perspective and the need for administration system organization

El Tribunal Supremo Federal y los bloqueos judiciales en las acciones de salud: una perspectiva crítica y la necesidad de organizar el sistema

\author{
Mariane Rabaioli Corbari Nardi ${ }^{1}$ \\ Vinícius Cerqueira de Souza² \\ Pedro Campos Marques ${ }^{3}$
}

Andréia Blau Brasil ${ }^{4}$

\begin{abstract}
Resumo
Objetivo: o presente estudo busca examinar o enfrentamento realizado pela Corte Superior na matéria relativa à saúde e, no transcurso, analisar a existência de balizas relativas à efetivação de bloqueios judiciais nos temas pendentes de julgamento. Métodos: fez-se uso do método dedutivo para analisar as decisões do Supremo Tribunal Federal relativo à matéria dos bloqueios judiciais em face do Poder Público nas demandas de saúde. Resultados: a matéria da judicialização da saúde encontra trânsito junto ao Supremo Tribunal Federal em múltiplos aspectos. O debate atual, consubstanciado nos Temas 6, 500 e 793, deriva de trajetória inaugurada com a Audiência Pública no 4 e transpassa pelo teor da decisão da STA no 175 . No que se refere ao cerne da efetivação de bloqueios judiciais nas demandas de saúde, a Proposta de Súmula Vinculante no 4 representou a busca pela estabilização do assunto. Conclusão: a despeito do amplo e atual debate no Supremo Tribunal Federal quanto à judicialização da saúde, a análise central do estudo conduz à verificação de reduzido enfrentamento do tema no que se refere aos bloqueios judiciais e à ausência de fixação pela Corte de critérios objetivos passíveis de estabelecer contornos para a atuação jurisdicional nos casos concretos.
\end{abstract}

Palavras-chave: Sistema Único de Saúde. Judicialização da saúde. Jurisprudência. Poder Judiciário.

\footnotetext{
${ }^{1}$ Procuradora do Estado do Rio Grande do Sul em exercício na 19a Procuradoria Regional de Frederico Westphalen/RS, Brasil; graduada em Ciências Sociais e Aplicadas pela Universidade Regional Integrada do Alto Uruguai e das Missões, campus de Frederico Westphalen. E-mail: mariane-corbari@pge.rs.gov.br

2 Procurador do Estado do Rio Grande do Sul em exercício na 16ª Procuradoria Regional de Gravataí/RS, Brasil; graduado em Direito pela Universidade Salvador (Unifacs); especialista em Direito Administrativo e em Direito Tributário e Planejamento pela Universidade Cândido Mendes. E-mail: vinicius-souza@pge.rs.gov.br

3 Procurador do Estado do Rio Grande do Sul em exercício na 18 ${ }^{a}$ Procuradoria Regional de Erechim/RS, Brasil; especialista em Direito Público pela Universidade para o Desenvolvimento do Estado e da Região do Pantanal (Uniderp). E-mail: pedro-marques@pge.rs.gov.br

4 Coordenadora Regional de Saúde Adjunta da 15 a Coordenadoria Regional de Saúde, unidade administrativa descentralizada da SES/RS; graduada em Direito pela Universidade de Passo Fundo. E-mail: andreiablau@saude.rs.gov.br
} 


\begin{abstract}
Objective: the present study seeks to examine the confrontation carried out by the Superior Court in the matter related to health and in the course of analyzing the existence of beacons related to the enforcement of judicial blockades in the subjects pending judgment. Methods: the deductive method was used to analyze the decisions of the Federal Supreme Court concerning the matter of judicial blockages in the face of the Public Power in health claims. Results: the matter of the judicialization of health finds transit with the Federal Supreme Court in multiple aspects. The current debate, embodied in Themes 6, 500 and 793, derives from the trajectory inaugurated with Public Hearing No. 4 and goes through the content of the STA No.175 decision. With regard to the core of effective judicial blockages in health demands, Binding Precedent Proposal No. 4 represented the search for stabilization of the subject. Conclusion: despite the broad and current debate in the Federal Supreme Court regarding the judicialization of health, the central analysis of the study leads to the verification of a reduced confrontation of the issue with regard to judicial blockages and the absence of the Court's determination of objective criteria to establish contours for judicial action in specific cases.

Keywords: Unified Health System. Judicialization of health. Jurisprudence. Judicial power.

\section{Resumen}

Objetivo: El presente estudio busca examinar la confrontación llevada a cabo por el Tribunal Superior en materia de salud y en el análisis de la existencia de balizas relacionadas con la ejecución de bloqueos judiciales en los sujetos pendientes de juicio. Métodos: El método deductivo se utilizó para analizar las decisiones de la Corte Suprema Federal sobre el tema de los bloqueos judiciales frente al Poder Público en los reclamos de salud. Resultados: La cuestión de la judicialización de la salud encuentra tránsito con la Corte Suprema Federal en múltiples aspectos. El debate actual, plasmado en los Temas 6, 500 y 793, deriva de la trayectoria inaugurada con la Audiencia Pública No. 4 y va más allá del contenido de la decisión STA No. 175. La Propuesta precedente vinculante No. 4 representaba la búsqueda de la estabilización del tema. Conclusión: a pesar del amplio y actual debate en la Corte Suprema Federal sobre la judicialización de la salud, el análisis central del estudio lleva a la verificación de una confrontación reducida del tema con respecto a los bloqueos judiciales y la ausencia de la determinación de criterios objetivos por parte de la Corte para establecer contornos para acciones judiciales en casos específicos.
\end{abstract}

Palabras clave: Sistema Único de Salud. Judicialización de la salud. Jurisprudencia Poder Judicial.

\title{
Introdução
}

O acesso à saúde pública no Brasil, materializado pelo Sistema Único de Saúde (SUS), de base descentralizada, previsto no artigo 196 da Constituição da República Federativa do Brasil de 1988 (CRFB) (1) e estruturado pela Lei no 8.080/90 (2), representou um grande avanço social ao estabelecer o dever do ente estatal de fornecer a universalização do acesso à saúde aos cidadãos.

A previsão, ainda que tenha delineado melhorias no setor, segundo Buíssa, 
Bevilacqua e Moreira Buíssa (3) não é efetiva. Daí advém o fenômeno da busca por decisões judiciais que concretizem os referidos direitos.

A possibilidade de constrição em contas públicas sem a análise casuística e determinada, ou ao menos mais aprofundada, além de gerar desestruturação no patrimônio público e nos programas do SUS, dependentes de tais verbas para sua concretização, soa contraditória às próprias finalidades a que o sistema serve, uma vez que a judicialização abarca apenas parte dos usuários.

Tal fato acaba por cindir a aplicação das verbas destinadas à saúde pública, já insuficientes em alguns casos para a cobertura constitucionalmente prevista: de um lado, há a necessidade de efetivação das políticas públicas de forma administrativa; e de outro, a existência de milhares de ações judiciais buscando terapêuticas alheias ao fornecimento coletivo, seja por critérios econômicos ou técnicos.

Segundo dados coletados, em valores absolutos, pela Secretaria da Saúde do Estado do Rio Grande do Sul em 2016, na rubrica da saúde do Estado do Rio Grande do Sul, os gastos para 0 atendimento de 61 mil pacientes em decorrência de decisões judiciais ultrapassaram 210 milhões de reais - incluídos aí os bloqueios judiciais. Por outro lado, para o tratamento de 230 mil pacientes de forma administrativa - ou seja, por meio do SUS -, o dispêndio foi de cerca de 82 milhões de reais (4).

A discrepância nos valores empregados revela uma inversão do emprego das verbas públicas destinadas à rubrica da saúde: o Poder Judiciário gasta mais com a saúde atendendo às demandas individuais do que o Poder Executivo o faz com a população que se submete aos protocolos clínicos existentes no SUS.

Tratando da judicialização e seus impactos na gestão pública, Naundorf, de Carli e Goulart destacam que o ingresso excessivo de demandas judiciais desorganiza o sistema público de saúde e, ao migrar o capital para o cumprimento de determinações judiciais, dificulta o desempenho de políticas públicas organizadas no âmbito da gestão administrativa para $o$ atendimento coletivo (5).

O presente estudo busca examinar o enfrentamento realizado pela Corte Superior na matéria relativa à saúde e, no transcurso, analisar a existência de balizas relativas à efetivação de bloqueios judiciais nos temas pendentes de julgamento. 


\section{Metodologia}

A metodologia utilizada quanto à abordagem é de caráter qualitativa e com base em procedimentos de pesquisa bibliográfica.

Para o desempenho, foram coletados elementos doutrinários e examinadas a resolução da Proposta de Súmula Vinculante (PSV) ํㅡ 4, as premissas estabelecidas na Audiência Pública oํ 4, a Decisão de Suspensão de Tutela Antecipada (STA) ㄲo 175 e os Recursos Extraordinários ํㅜ 566.471/RN, 657.718/MG e oㅜ 855.178/SE.

$\mathrm{Na}$ obtenção das conclusões, alicerçou-se no método dedutivo, visando a análise do enfrentamento pelo STF relativo à matéria dos bloqueios judiciais em face do Poder Público nas demandas de saúde destacadas e com repercussão geral reconhecida.

\section{Proposta de Súmula Vinculante no 4}

Do sobrestamento da proposta relativa à possibilidade de bloqueio de verbas públicas para o fornecimento de tratamentos médicos

Como sinalizado, enfrenta-se neste trabalho a hipótese de que o tratamento postulado deve ser prestado pelo ente demandado frente a uma ordem judicial, situação que rotineiramente descamba na realização de constrição judicial sobre as verbas públicas.

Tratando sobre a judicialização das políticas públicas, Marques, Rocha, Asensi e Monnerat relatam que o Poder Judiciário tem buscado se debruçar de forma mais ordenada sobre o tema da saúde (6). Delineiam, ainda, que o ato de julgar em saúde não deve estar desvinculado de outros parâmetros e, em razão do protagonismo judicial, estabelece-se a necessidade de atuação coordenada e estratégica (6).

Nesse contexto, o tema dos bloqueios judiciais em questões de saúde foi objeto da PSV no 4, apresentada pelo Defensor Público Geral da União, com amparo no art. 3ํㅡ, VI, da Lei oㅜ 11.417/2006, com dois pleitos direcionados ao Supremo Tribunal Federal (STF): i) fixação da responsabilidade solidária dos entes públicos no fornecimento de fármacos e tratamentos médicos àqueles que não possuem condições econômicas para o custeio; e ii) a possibilidade de bloqueio de verbas públicas para o fornecimento desse tratamento, afastando-se a alegação de ofensa ao artigo 100, caput e $\S 2^{\circ}$ da CRFB (7).

Os termos da PSV no 4 estão disponibilizados no sítio eletrônico do STF e, na parcela 
referente à realização de bloqueios, está assim registrada:

\begin{abstract}
Assim, roga o Defensor Público-Geral da União seja editada súmula vinculante tornando expressa a possibilidade de bloqueio de valores públicos para o fornecimento de medicamento e tratamento médico ao carente, comprovada a necessidade do fármaco ou da intervenção médica, restando afastada, por outro lado, a alegação de que tal bloqueio fere o artigo 100, caput e §º da Constituição de 1988, como já assentado pelos Eminentes Ministros (7).
\end{abstract}

Processada regularmente a petição do proponente, restou reconhecida a inadequação formal da edição de súmula referente ao segundo tema tratado: os argumentos da decisão delinearam a ausência de fundamentação constitucional nas decisões citadas na proposta e, não menos importante, consideraram que a jurisprudência da Corte Suprema sobre o tema não é pacífica. Restou então, sobrestada parcialmente, a tramitação da proposta, agora concentrada na tese da solidariedade no fornecimento de tratamentos de saúde (7).

A observação é posta no teor da decisão do Ministro Presidente Ricardo Lewandowski, analisando a manifestação da União como interessada no processamento da proposta:

\begin{abstract}
Por outro lado, quanto à inadequação formal da proposta em relação à possibilidade de bloqueio de valores públicos para que seja fornecido medicamento e oferecido tratamento médico aos carentes, creio que a razão está com a União.

É que, como bem demonstrado, a jurisprudência da Corte sobre o tema não é pacífica, seja porque em diversas decisões não se analisou a questão porque o bloqueio de verbas foi deferido com base em normas infraconstitucionais - nesse sentido menciono o Al 597.182-AgR/RS, Rel. Min. Cezar Peluso, e o Al 553.712$\mathrm{AgR} / \mathrm{RS}$, de minha relatoria -, seja porque em situações semelhantes, e à luz do caso concreto, suspensões de segurança, de liminar e de tutela antecipada podem ser deferidas para sustar o bloqueio de verbas - nesse sentido, a SL 254/RS, Rel. Min. Presidente (7)
\end{abstract}

O sobrestamento da edição da súmula vinculante considerou, inclusive, a ocorrência, em casos concretos, de decisões contrárias à efetivação de constrição em contas públicas, demonstrando a inexistência de uniformidade quanto ao ponto debatido e a necessidade de rediscussão da matéria - merecedora de profunda avaliação -, principalmente pelas nuances que podem ser verificadas e danos que poderiam ser causados como consequência da vinculação decorrente da edição de súmula da espécie (7) 
Desligamento entre a realidade e o processo: abandono do princípio processual da adequação

Conforme sinalizado, a PSV no 4 sugere que o bloqueio judicial seja autorizado após simples comprovação de que há a necessidade do medicamento ou do tratamento. A sugestão, portanto, envolve i) o engessamento do procedimento para satisfação da obrigação; e, mais que isso, ii) a perigosa simplificação dos pressupostos para a identificação do dever de prestação.

Existe um desacerto da parte da proposta referente à simplificação da forma de cumprimento de decisões judiciais. Há hipóteses em que a concretização do direito individual deve ser harmonizada com o interesse da coletividade ou, para evitar discussões terminológicas sobre o conceito de interesse público, é preciso buscar meios de conciliar o direito do paciente demandante e o direito do paciente que seguiu os protocolos administrativos e que será diretamente impactado pelo processo judicial.

O ordenamento jurídico admite 0 estabelecimento de formas executivas individualizadas, quando o direito material envolvido é peculiar. É o caso, por exemplo, da execução contra a Fazenda Pública, em que a cobrança é instrumentalizada por precatório ou requisição de pequeno valor, tendo em vista, dentre outras finalidades, a necessidade de programação do orçamento disponível para concretizar as políticas públicas, de modo a evitar o esgotamento do capital estatal (1).

Admite-se, pois, em nível constitucional, a postergação da satisfação de um crédito líquido, certo e exigível. A relativização do interesse é admitida pelo constituinte originário, pois viabiliza a perpetuação dos interesses da sociedade sem anular o direito individual.

A legislação infraconstitucional também contempla exemplos de relativização da forma de execução das obrigações em nome de um interesse maior. A Lei de Recuperações Judiciais reconhece a base econômica da CRFB e adapta a técnica executiva em hipóteses específicas. Dessa forma, a exigibilidade tradicional do crédito acaba subordinada ao interesse superior de, segundo o art.47 da Lei nº 11.101/2005, "permitir a manutenção da fonte produtora, do emprego dos trabalhadores e dos interesses dos credores, promovendo, assim, a preservação da empresa, sua função social e o estímulo à atividade econômica" (8).

Note-se que, nesse caso, é possível que o direito de um credor específico fique 
inadimplido se, apesar das extensas tentativas de recuperação judicial, o devedor reste insolvente. O aparente desamparo da lei a esse credor é resultado de uma análise economicamente realista e que, por isso, atende um espectro maior de interessados. Ainda que o resultado final seja o exaurimento dos recursos, a organização das despesas possibilita melhor distribuição de recursos entre os credores.

Conquanto não se possa falar em falência do Estado e nem a jurisprudência admite que o necessitado de medicamentos aguarde o processamento da fila de precatórios, há que ser identificado um meio termo.

Ainda com olhos no Código de Processo Civil (CPC) de 1973, José Roberto dos Santos Bedaque (9) identificava a tendência de superação do procedimento ordinário, com a adaptação do iter procedimental às peculiaridades do direito material discutido. Já àquela época o eminente processualista sinalizava a necessidade de conferir maior "elasticidade", ou "adaptabilidade" do procedimento à luz do direito material discutido no processo.

De modo similar, José Carlos Barbosa Moreira apontava a crescente "consciência cada vez mais clara da função instrumental do processo e da necessidade de fazê-lo desempenhar de maneira efetiva o papel que lhe toca" (10).

Nessa linha, advertia que:

Se o processo é instrumento de realização do direito material, o resultado do seu funcionamento deve situar-se a uma distância mínima daquele que produziria a atuação espontânea das normas substantivas, e já constitui uma desgraça a impossibilidade de fazer coincidir precisamente um e outro (10).

Assim equacionada a questão, a distância entre o resultado processual e o cumprimento espontâneo serve de régua para o fracasso do procedimento aplicado.

No caso dos bloqueios judiciais irrestritos, como já se adiantou, a distância é significativa: o custo para o cumprimento administrativo é significativamente inferior à aquisição judicial, e a divergência de valores consiste, em última análise, na redução dos valores para aplicação na mesma área social. Ademais, realização irrestrita, desordenada e imprevisível de bloqueios sobre as contas públicas torna praticamente impossível a gestão eficaz do SUS, sobretudo em um país de dimensões continentais como o Brasil.

Já sob a vigência do Novo Código de Processo Civil, a doutrina contemporânea não ignora o alerta dos seus predecessores. Como o fazem Marinoni, Arenhart e Mitidiero (11), a técnica processual deve ser necessária e idônea à tutela do direito, mas também 
preocupada com a menor restrição à esfera jurídica do réu:

Porém, a legitimidade do emprego da técnica processual não decorre apenas da sua relação de adequação com o plano do direito material. Esse controle deve ser feito a partir da proporcionalidade, ou melhor, especialmente a partir da sua subnorma da necessidade (meio idôneo e menor restrição possível). Na verdade, a técnica processual deve ser necessária e idônea à tutela do direito, mas também a que traz a menor restrição à esfera jurídica do réu. É claro que, antes de tudo, o meio processual deve ser idôneo à tutela do direito. O juiz somente deve se preocupar com a menor restrição possível após ter identificado o meio idôneo à tutela do direito (11).

A observação é especialmente relevante em se tratando de demandas de saúde, casos em que a restrição à esfera jurídica do réu consiste, a rigor, em restrição dos recursos disponíveis aos demais pacientes vinculados ao SUS e em quebra da ordem dos atendimentos.

Com todas as vênias, a PSV no 04 caminha no sentido oposto ao da evolução processual. Ao engessar em uma única fórmula o cumprimento das decisões, a proposta ignora décadas de construção doutrinária quanto à necessidade de adequação da tutela judicial ao rito processual e de flexibilização deste às necessidades do caso concreto.

A proposta mostra-se ainda mais danosa quando se tem em conta que não há qualquer formulação em relação ao tipo de tratamento buscado, à possibilidade de aquisição no plano administrativo, à efetiva urgência da aquisição ou à periodicidade da constrição, culminando na total indiferença do processo em relação ao caso concreto.

\section{Bloqueios judiciais: análise à luz da temática no Supremo Tribunal Federal}

Posta a crítica relacionada à proposta de utilização irrestrita da técnica de bloqueios judiciais, conforme buscou sedimentar a PSV n.. 4, cabe no momento a referência aos julgamentos sobre o fornecimento de medicamentos pelo Poder Público em trânsito no STF. Embora não completamente acomodada nas decisões recentemente proferidas e cuja publicação se aguarda, a temática da judicialização na saúde passou a prever critérios que ultrapassam simples exigência de prescrição do medicamento ou tratamento ao paciente.

A Corte Constitucional tem se voltado ao tema do direito à saúde em diversos julgados e demonstrado preocupação corrente com a crescente judicialização. Vê a necessidade de estabelecimento de parâmetros para a qualificação desse evento e de uniformização de questões relevantes, com base nos paradigmas apresentados. 
Elencando os momentos e decisões nos quais as ações de saúde evidenciaram-se na Corte Constitucional, buscar-se-á verificar, em seu conteúdo: i) a ausência do tratamento de questão específica quanto à efetivação dos bloqueios judiciais; ii) o destaque à importância de enfrentamento direto do ponto para o estabelecimento de parâmetros na concessão de determinação de constrição de valores públicos, visando o equacionamento das questões que se apresentam nos casos concretos.

Inicialmente, destaca-se a realização da Audiência Pública n.ํ 4, no ano de 2009, convocada pelo então Presidente do STF, Ministro Gilmar Ferreira Mendes, momento em que especialistas de diversas áreas delinearam aspectos relativos às demandas de saúde, visando fornecer subsídios para os processos de competência da Presidência que tramitavam à época (12).

Mendes e Branco destacam que a audiência visou promover a participação social e propiciou o debate por meio de depoimentos de profissionais com experiência na área da saúde, com o objetivo de esclarecer aspectos técnicos da expertise dos especialistas. Os dados coletados forneceram embasamento para a decisão da Suspensão de Tutela Antecipada no 175, na qual, diante da preocupação com o ativismo judicial crescente, delinearam-se referências para a solução judicial nos casos concretos $(13,14)$.

O despacho convocatório do referido estudo traçou os pontos a serem debatidos, cujo destaque merece espaço em razão da atualidade de sua estruturação e discussão na Corte Constitucional:

1) Responsabilidade dos Entes da Federação em matéria de direito à saúde;

2) Obrigação do Estado de fornecer prestação de saúde prescrita por médico não pertencente ao quadro do SUS ou sem que o pedido tenha sido feito previamente à Administração Pública;

3) Obrigação do Estado de custear prestações de saúde não abrangidas pelas políticas públicas existentes;

4) Obrigação do Estado de disponibilizar medicamentos ou tratamentos experimentais não registrados na ANVISA ou não aconselhados pelos Protocolos Clínicos do SUS;

5) Obrigação do Estado de fornecer medicamento não licitado e não previsto nas listas do SUS;

6) Fraudes ao Sistema Único de Saúde. (12)

De acordo com os objetivos a serem discutidos, revela-se que a audiência buscou realizar um cotejo entre o sistema da saúde e o sistema da justiça, com vistas a estabelecer o diálogo necessário e conduzir um debate até então não realizado. 
Em importante estudo, que analisa os discursos 5 à luz da teoria de Niklas Luhmann, Oliveira, Delduque e Mendonça concluem que o resultado advindo da discussão no STF, nas categorias propostas, buscou a superação das questões debatidas mediante aprendizado mútuo entre os dois sistemas. Os autores referem que a tendência de uniformização das decisões judiciais tem o condão de gerar efetivos ganhos práticos para a organização do sistema público de saúde e balizar as decisões e procedimentos do Poder Judiciário (15).

Importa reconhecer que as considerações fruto da Audiência Pública № 4 embasaram a formulação de decisão na STA nํ175, na qual discutia-se a responsabilidade solidária nos três níveis estatais para o fornecimento de medicamento de alto custo não registrado na Anvisa, em situação concreta discutida nos autos de Apelação Cível em trâmite na $1^{\underline{a}}$ Turma do Tribunal Regional Federal da 5 ${ }^{\underline{a}}$ Região (16).

Tangenciando os aspectos analisados pelo STF na citada STA ํㅜ 175 , diante da necessidade de elucidação do caso frente à alegada grave lesão à ordem, economia, saúde e segurança pública, ressalta-se: (i) indispensabilidade de verificação, a critério da medicina baseada em evidências, de existência e suficiência das políticas públicas para atendimento do caso concreto; (ii) fornecimento de fármaco sem registro na Anvisa; (iii) repartição de competências e a responsabilidade solidária entre os entes demandados; (iv) alto custo do tratamento; (v) grave lesão à ordem, economia, saúde e segurança pública (16).

Em seu voto, o Ministro Gilmar Mendes destaca que a judicialização da saúde envolve gestores públicos, sociedade civil organizada, profissionais atuantes na área da saúde, além dos operadores do direito, considerando que as decisões judiciais têm a tendência a gerar desgaste entre o emissor da decisão e seus executores, principalmente pela inexistência de fundo orçamentário para amparar a totalidade das decisões proferidas (16).

$\mathrm{Na}$ esteira do discutido nos dois momentos destacados - a Audiência Pública ํㅡ $4 \mathrm{e}$ os pontos tangenciados no julgamento do AgR na STA no 175/CE -, verifica-se que muitas respostas dependem da integração entre os sistemas da saúde e da justiça, sob pena do maior enfraquecimento da macrojustiça e proliferação das decisões judiciais ante a ausência de parâmetros para as questões de relevância apontadas e o ativismo judicial em

\footnotetext{
${ }^{5}$ Disponíveis em http://www.stf.jus.br
} 
ascendência.

É necessário apontar que os debates realizados na Audiência Pública ㄲo 4 e no julgamento da STA o 175/CE encontram eco nos julgamentos pendentes junto à Corte Suprema na matéria de saúde, destacando-se as seguintes repercussões gerais: i) Tema 6, tratado no RE-RG no $566.471 / R N$, sobre o fornecimento de medicamento de alto custo a paciente portador de enfermidade grave que não apresente condições financeiras para custeio por meios próprios (17); ii) Tema 500, no RE-RG no 657.718/MG, que trata do dever de fornecimento pelo Estado de medicamento não registrado na Anvisa(18); iii) Tema 793, discutido no RE-RG no 855.178, cujo cerne discute a responsabilidade solidária dos entes federados nas prestações de saúde (19)

Do apontado, apura-se que o direito à saúde judicializado em face do Poder Público e suas limitações se encontram ainda em discussão e urge a necessidade de enfrentamento das questões postas, para que as controvérsias fundamentadas possam ser dirimidas na macrojustiça e passem a ter reflexos importantes nos aspectos individualmente discutidos nos processos judiciais de instâncias inferiores.

Feitas as anotações acerca da tramitação da judicialização da saúde no STF, necessário questionar sobre a ausência de enfrentamento direto aos bloqueios judiciais decorrentes de decisões antecipatórias ou definitivas.

Reconhece-se, todavia, que o assunto relativo aos bloqueios judiciais restou perpassado pela Corte Suprema, quando da análise do Recurso Extraordinário (RE) no 607.582/RS, interposto em 2007 em razão de alegada ofensa ao artigo 100, $\S 2^{\circ}$ da CRFB, considerando o deferimento de sequestro de valores públicos no caso de descumprimento de ordem judicial. Ponderou-se ainda que a constrição gera desequilíbrio orçamentário, em violação ao artigo 167, II e VII da Carta Constitucional (20).

A Ministra Relatora indicou que a jurisprudência da Corte Constitucional apontava para a possibilidade de utilização dos bloqueios como forma de efetivação das prestações referentes ao direito à saúde. A fundamentação do voto consistiu na referência aos precedentes judiciais e culminou com o reconhecimento da repercussão geral sobre o tema, que foi julgado pelo Plenário Virtual (20).

A repercussão geral foi estabelecida com base em referência do Tribunal Constitucional às suas próprias decisões. De todo modo, a proposição referente às 
constrições judiciais nas contas públicas para o cumprimento de determinações em demandas de saúde permanece em voga nos Tribunais. Soa adequado o reexame da matéria à luz da nova realidade fática e com análise da constitucionalidade da aplicação das técnicas processuais flexíveis, que tinham crescente apoio doutrinário à época do Código Buzaid e encontram amplo eco no novo CPC.

Seguindo essa ótica, no RE nº 607.582/RS busca-se o necessário exame da jurisprudência que versa sobre a matéria diante das consequências advindas de decisões da espécie. Destaca-se o imperioso debate constitucional para a definição de critérios mínimos balizadores dos bloqueios judiciais, sob pena de inviabilização de toda a política pública de saúde, na medida em que comprometem partes significativas dos orçamentos públicos (20).

No âmbito da Corte Constitucional, espera-se novo contraponto de ideias no julgamento do mérito do $R E$ n $566.471 / R N$, pautado para outubro de 2019 , no qual se discutirá o fornecimento de medicamentos que não se encontram descritos nos protocolos clínicos do SUS, paradigma com reflexo direto em razão da prejudicialidade.

A inevitabilidade quanto ao estabelecimento de critérios mínimos é manifesta e espera-se pelo espaço cabível para tanto, considerando que o Tribunal assinala pela fixação de parâmetros para o fornecimento de tratamentos pelo Poder Público, sendo reflexo importante a discussão sobre as formas de cumprimento das decisões judiciais concessivas.

De modo conciso, é possível dizer que, passados dez anos do aprofundamento do estudo da saúde pela Corte Suprema, verifica-se - de acordo com o Despacho de Convocação de Audiência Pública (12) e termos da decisão da STA no 175 (16), em cotejo com os Recursos Extraordinários apresentados cujo caráter de Repercussão Geral $(17,18,19)$ encontra-se reconhecido - que pouco se avançou no sistema da justiça de forma concreta, o que tem contribuído significativamente para a manutenção do crescimento de demandas judiciais individualmente propostas.

Ainda que os bloqueios judiciais decorrentes das demandas possuam a força de inviabilizar a gestão pública de orçamentos na área da saúde, inexiste até o presente momento o enfrentamento direto e necessário quanto a critérios específicos que balizem a atuação jurisdicional, o que se espera ver implementado diante da necessidade de correção de distorções que ainda decorrem em determinadas decisões judiciais. 


\section{Conclusão}

O panorama da judicialização em saúde se encontra em expansão numérica e em diversidade de situações postas. A via da ação judicial acaba por estabelecer corriqueiro acesso à saúde e, ao mesmo tempo que evidencia as deficiências do sistema público, contribui para uma condução do orçamento pelo Poder Judiciário, na medida que vincula verbas públicas, para a satisfação de interesses prescritos em demandas individuais não atendidas, em políticas alcançadas à coletividade.

Importante notar que a preocupação com as questões reflexas à judicialização, entre elas a ocorrência de bloqueios e a necessidade de otimização do cumprimento, além de qualificação da gestão, é corrente debate quando se fala em demandas de saúde.

Frente ao tema, a ideia apresentada na PSV no 4 encontra-se em desacordo com a doutrina processual e com os ricos debates registrados nos Tribunais. Isso porque, como apresentada, deixa de considerar a análise quanto à necessidade de adequação do cumprimento da tutela jurisdicional ao rito processual posto. Também desconsidera a imperativa flexibilização das medidas de bloqueio em determinados casos concretos e generaliza a possibilidade de constrição judicial sem a fixação de critérios objetivos.

Tendo por base o transcurso do tema desde a realização da Audiência Pública nำ4, perpassando pelo teor da decisão proferida na STA no 175 e os preceitos nela estabelecidos, não se pode olvidar da importância da rediscussão pelo STF nas questões cujas Repercussões Gerais possuem pauta para resolução próxima. A estruturação e indicação de critérios que possam balizar a atuação jurisdicional frente à interpretação constitucional tem o condão de resolver e universalizar, no nível da macrojustiça, o atendimento derivado da provocação do Poder Judiciário.

Diante do exposto, infere-se que persiste a necessidade de indicação de balizas para a atuação jurisdicional, não apenas quanto ao mérito das demandas de saúde, mas igualmente aos seus efeitos relacionados ao cumprimento das decisões judiciais, aqui destacando-se a efetivação de bloqueios para a aquisição particular de medicamentos e/ou tratamentos. Contudo, os parâmetros a serem delineados nos acórdãos cuja publicação se aguarda, ainda que possuam relação intrínseca com o tema dos bloqueios judiciais, não importam em seu enfrentamento direto. É uma situação que, diante dos reflexos práticos do 
orçamento da rubrica relacionada na gestão pública, carece de análise e merece ser igualmente estabelecida, uma vez que as decisões judiciais não podem ignorar os requisitos técnicos da área médica e, decerto, não podem negligenciar o impacto econômico e político das constrições realizadas.

\section{Referências}

1. Brasil. Constituição Federal, de 05 de outubro de 1988. Disponível em: http://www.planalto.gov.br/ccivil_03/constituicao/constituicaocompilado.htm [Acesso em 08.out.2019]

2. Brasil. Lei $n^{\circ} \mathbf{8 . 0 8 0}$, de 19 de setembro de 1990. Dispõe sobre as condições para a promoção, proteção e recuperação da saúde, a organização e o funcionamento dos serviços correspondentes e dá outras providências. Brasília, 20 set 1990. Disponível em: http://www.planalto.gov.br/ccivil_03/leis//8080.htm [Acesso em 08.out.2019].

3. Buíssa L, Bevilacqua L, Moreira FHBB. Impactos Orçamentários da Judicialização das Políticas Públicas de Saúde. Coletânea direito à saúde: dilemas do Fenômeno da Judicialização da Saúde. 2018, 2: 26-50. Disponível em: www.conass.org.br/biblioteca. [Acesso em 15.jul.2019].

4. Rio Grande do Sul. Secretaria Estadual de Saúde. Dados Institucionais. [Acesso em 26.ago.2019].

5. Naundorf B, de Carli P, Goulart B. O Estado do Rio Grande do Sul e os Impactos da Judicialização da Saúde na Gestão Pública. Coletânea direito à saúde: 2018, 2: 208-217. Disponível em: www.conass.org.br/biblioteca [Acesso em 15.jul.2019].

6. Marques A, Rocha C, Asensi F, Monnerat DM. Judicialização da saúde e medicalização: uma análise das orientações do Conselho Nacional de Justiça. Estudos Avançados. 2019, 33: 217-234. Disponível em http://www.scielo.br/scielo.php?script=sci_arttext\&pid=S01030142019000100217\&lng=pt\&nrm=iso [Acesso em 15.jul.2019].

7. Brasil. Supremo Tribunal Federal. PSV 4. Proponente: Defensor Público-Geral Federal. Brasília, 2019. Disponível em: http://portal.stf.jus.br/processos/detalhe.asp?incidente $=2652147$ [Acesso em 20.jul.2019]

8. Brasil. Lei no 11.101, de 9 de fevereiro de 2005. Regula a recuperação judicial, a extrajudicial e a falência do empresário e da sociedade empresária. Brasília, 9 fev 2005. Disponível em: http://www.planalto.gov.br/ccivil_03/_Ato2004-2006/2005/Lei/L11101.htm [Acesso em 09.out.2019]

9. Bedaque JRS. Direito e Processo. São Paulo: Editora Malheiros, 1995. 
10. Moreira JCB. Tendências Contemporâneas do Direito Processual Civil. Revista de Processo. 1983; (31): 199-209. Disponível em https://revistadostribunais.com.br [Acesso em 27.jul.2019].

11. Marinoni LG, Arenhart SC, Mitidiero D. O Novo Processo Civil. 3.ed. São Paulo: Editora Revista dos Tribunais, 2017.

12. Brasil. Audiência Pública no 4/2019 do Supremo Tribunal Federal. Audiência Pública convocada pelo Presidente do Supremo Tribunal Federal à época, Ministro Gilmar Mendes, para subsidiar o julgamento de processos que discutiam a concretização do direito à saúde (art. 196 da Constituição Federal), a partir do oferecimento de medicação e tratamento pelo Poder Público. Brasília, 27 abr a 07 maio 2009. Disponível em: http://www.stf.jus.br/portal/audienciaPublica/audienciaPublica.asp?paginaAtual=2\&tipo=real izada\# [Acesso em 09.out.2019].

13. Mendes GF, Branco PGG. Curso de Direito Constitucional. 14.ed. rev. São Paulo: Saraiva Educação, 2019.

14. Brasil. Supremo Tribunal Federal. Brasília. 2009. Disponível em: http://www.stf.jus.br/portal/cms/verTexto.asp?servico=processoAudienciaPublicaSaude [Acesso em 20.jul.2019].

15. Santos AO, Delduque MC, Mendonça, AVM. Os discursos na Audiência Pública da Saúde e seu impacto nas decisões do Supremo Tribunal Federal: uma análise à luz da teoria dos sistemas sociais. Saúde e Sociedade. 2015, vol.24, suppl.1: 184-192. Disponível em: http://dx.doi.org/10.1590/S0104-12902015S01016. [Acesso em 21.jul.2019].

16. Brasil. Supremo Tribunal Federal. Suspensão de Tutela Antecipada 175 - AgR/CE. Agravante: União Federal. Agravada: Ministério Público Federal, Município de Fortaleza, Estado do Ceará. Relator: Ministro Gilmar Mendes, Brasília, 17 mar 2010. DJe oo 76. Publicação: 30 abr. 2010. Disponível em: redir.stf.jus.br/paginadorpub/paginador. jsp?docTP=AC\&doclD=610255 [Acesso em 20 jul.2019].

17. Brasil. Supremo Tribunal Federal. RE 566471. Recorrente: Estado do Rio Grande do Norte. Recorrido: Carmelita Anunciada de Souza. Relator: Ministro Marco Aurélio, Brasília, 2019. Disponível em: http://www.stf.jus.br/portal/jurisprudenciaRepercussao/verAndamento Processo.asp?incidente $=2565078 \&$ numeroProcesso $=566471$ \& classeProcesso $=$ RE \&numero Tema $=6$ [Acesso em 31 jul.2019].

18. Brasil. Supremo Tribunal Federal. RE-RG 657.718/MG. Recorrente: Alcirene de Oliveira. Recorrido: Estado de Minas Gerais. Relator: Ministro Marco Aurélio. Brasília, 2019. Disponível em: http://www.stf.jus.br/portal/jurisprudenciaRepercussao/verAndamento Processo .asp ?incidente $=4143144 \&$ numeroProcesso $=657718 \&$ classeProcesso $=$ RE $\&$ numer oTema $=500$ [Acesso em 31.jul.19]. 
19. Brasil. Supremo Tribunal Federal. RE-RG 855.178. Recorrente: União Federal. Recorrido: Maria Augusta da Cruz Santos. Relator: Ministro Luiz Fux. Brasília, 2019. Disponível em: http://www.stf.jus.br/portal/jurisprudenciaRepercussao/verAndamentoProcesso.asp?inciden te $=4678356$ \& numeroProcesso $=855178$ \& classeProcesso $=$ RE\&numeroTema $=793$.

20. Brasil. Supremo Tribunal Federal.RE 607582. Recorrente Estado do Rio Grande do Sul. Recorrido: Marina Carolina Morais Paz. Relator: Min. Ellen Gracie. Disponível em: http://portal.stf.jus.br/processos/detalhe.asp?incidente=3819070 [Acesso em 09.out.2019].

Como citar este artigo:

Nardi MRC, Souza VC, Marques PC, Brasil AB. O Supremo Tribunal Federal e os bloqueios judiciais nas ações de saúde: perspectiva crítica e a necessidade de organização do sistema. Cadernos Ibero-Americanos de Direito Sanitário. 2019 out./dez.; 8(4): 103-118.

http://dx.doi.org/10.17566/ciads.v8i4.568 